\title{
Políticas públicas de mobilidade urbana e as práticas de priorização de projetos: Uma abordagem multicritério
}

\author{
Public policies on urban mobility and practices to project prioritization: A multi-criterial approach \\ Políticas públicas de movilidad urbana y prácticas de priorización de proyectos: Un enfoque \\ multicriterio
}

Recebido: 13/07/2021 | Revisado: 21/07/2021 | Aceito: 23/07/2021 | Publicado: 31/07/2021

\author{
Graziana Donata Punzi de Siqueira \\ ORCID: https://orcid.org/0000-0002-0974-0182 \\ Universidade Federal do ABC, Brasil \\ E-mail: gra_siqueira@hotmail.com \\ Josiane Palma Lima \\ ORCID: https://orcid.org/0000-0002-8250-5269 \\ Universidade Federal de Itajubá, Brasil \\ E-mail: jplima@unifei.edu.br \\ Júlia Barros dos Santos \\ ORCID: https://orcid.org/0000-0002-0994-1793 \\ Universidade Federal de Itajubá, Brasil \\ E-mail: jplima@unifei.edu.br
}

\begin{abstract}
Resumo
O objetivo do trabalho foi desenvolver um modelo multicritério de apoio à decisão para escolha de projetos prioritários que concretizam políticas públicas de mobilidade urbana por meio do método Analytic Hierarchy Process. Os fatores influentes do processo decisório foram escolhidos junto aos gestores públicos da área de mobilidade de três cidades do Estado de São Paulo. A importância relativa dos fatores foi determinada através de julgamentos de gestores e especialistas da área acadêmica. O fator determinante "Origem da demanda" foi o de maior importância relativa e, neste grupo, destaca-se o fator influente "política urbanística", que consiste em projetos previstos no Plano diretor ou de Mobilidade Urbana. O modelo foi validado por meio de sua aplicação para priorização de dois projetos em Lorena. O estudo contribui com o planejamento da mobilidade mediante proposição do modelo e fornece uma ferramenta de apoio à decisão para direcionar a execução de projetos de mobilidade.
\end{abstract}

Palavras-chave: Mobilidade urbana sustentável; Políticas públicas; Análise multicritério; Desenvolvimento e ambiente urbano.

\begin{abstract}
The work aimed at structuring a multicriteria decision support model for choosing priority projects that materialize public policies on urban mobility through the Analytic Hierarchy Process method. The influential factors of the decision-making process were chosen with the public experts in the mobility area of three cities in the State of São Paulo. The relative importance of the factors was were assigned by means of judgments by public and academic experts. The determining factor "Origin of demand" was the most important and, in this group, the influential factor "urban policy" stands out, which consists of projects foreseen in the Master Plan or in the Urban Mobility Plan. The model was validated through its application to prioritize two projects in Lorena city. The study contributes to mobility planning by proposing the model and provides a decision support tool to guide the execution of mobility projects.

Keywords: Sustainable urban mobility; Public Policies; Multicriteria decision-making; Development and urban environment.

\section{Resumen}

El objetivo del trabajo fue desarrollar un modelo multicriterio de apoyo a la decisión para la elección de proyectos prioritarios que implementen políticas públicas de movilidad urbana a través del método de Proceso Analítico de Jerarquía. Los factores influyentes en el proceso de toma de decisiones fueron elegidos entre los gestores públicos del área de movilidad de tres ciudades del Estado de São Paulo. La importancia relativa de los factores se determinó a través de los juicios de gerentes y expertos en el campo académico. El factor determinante "Origen de la demanda" fue el de mayor importancia relativa y, en este grupo, destaca el factor influyente "política urbana", que consiste en
\end{abstract}


proyectos previstos en el Plan Director o Movilidad Urbana. El modelo fue validado a través de su aplicación para priorizar dos proyectos en Lorena. El estudio contribuye a la planificación de la movilidad proponiendo el modelo y proporciona una herramienta de apoyo a la decisión para orientar la ejecución de proyectos de movilidad.

Palabras clave: Movilidad urbana sostenible; Políticas públicas; Análisis multicritério; Desarrollo y entorno urbano.

\section{Introdução}

As cidades são caracterizadas por diversos problemas sociais, econômicos e ambientais que impactam significativamente a qualidade de vida das pessoas que residem no meio urbano (Martins et al., 2020). Neste contexto, muitos desses problemas, como acidentes de trânsito, ruídos, poluição do ar e restrições de mobilidade para certos grupos da população, são atribuídos ao aumento dos deslocamentos nas cidades (Silva et al., 2015). O planejamento da mobilidade, em especial o planejamento do sistema de transporte, tem sido amplamente reconhecido como contribuinte para a promoção da sustentabilidade do meio urbano (Hidalgo e Huizenga, 2013; Haghsenas et al., 2015; Guerra et al.,2016). Assim, a Mobilidade Urbana, que antes era analisada apenas pelos aspectos quantitativos das viagens realizadas, passou a ser entendida de maneira mais complexa, analisando-se as condições dos deslocamentos sob vários aspectos: social, econômico, político, cultural e ambiental (Magagnin e Silva, 2008; Seabra, 2013). Além disso, com a pandemia e as restrições de mobilidade impostas pelo governo federal esse setor ganhou uma importância ainda maior como fator de qualidade de vida, devendo proporcionar aos indivíduos acesso seguro a serviços públicos e funções sociais (Lima et al.,2019).

No contexto brasileiro, antes da pandemia, já havia ocorrido um aumento significativo do transporte individual, com um aumento de $24 \%$ de veículos entre 2009 e 2011, gerando, entre outras consequências, o surgimento de congestionamento em cidades pequenas e médias e o aumento do tempo gasto em deslocamentos (Fix; Ribeiro; Prado, 2015). Tendo em vista a crise urbana ocasionada pelo aumento do uso de veículos motorizados individuais, tornou-se necessária uma política nacional orientadora e coordenadora de esforços e investimentos dos vários níveis de governo, do setor privado e da sociedade civil. Como resultado desse processo, a Lei 12.587 de 03 de janeiro de 2012, instituiu a Política Nacional de Mobilidade Urbana, um instrumento de política de desenvolvimento urbano que tem por objetivo a integração dos modos de transporte e a melhoria da acessibilidade e mobilidade no território do município (Brasil, 2012). Entretanto, o processo de gestão da mobilidade urbana sustentável enfrenta grandes desafios no planejamento e execução de projetos que implementem as diretrizes apontadas na lei.

No geral, o planejamento e as transformações do meio urbano são de extrema complexidade. O processo de tomada de decisão no contexto urbano é caracterizado pelo envolvimento de vários atores com diferentes visões e objetivos, por aspectos multidimensionais a serem considerados, que muitas vezes são conflitantes, e por escalas de análise de vários níveis (Caprioli e Bottero, 2021). Isto também se aplica para o planejamento e intervenções na área de mobilidade. Na literatura, a mobilidade urbana sustentável, bem como as políticas que a executam, vem sendo objeto de pesquisas em diversos campos de conhecimento e sob vários aspectos (Felix et al., 2019). Existem estudos, como o de Costa (2008) e Seabra (2013) que propõem índices para avaliação de mobilidade urbana nos municípios. Estudos como o de Campos (2006) e Hidalgo e Huizenga (2013) relacionam mobilidade urbana aos fatores econômico, social e ambiental. Boareto (2008) e Lucian (2015) relacionam as políticas públicas de mobilidade urbana ao desenvolvimento sustentável das cidades. Verifica-se também o desenvolvimento de estudos voltados a lugares específicos e acessibilidade, traçando-se diagnósticos e propostas, como os de Silva et al. (2008), Pontes (2011), Miranda e Silva (2012), Silva et al. (2015), Sakamoto e Lima (2016), Lima et al. (2019), Machado e Lima (2019). Observa-se que muitos desses trabalhos propõem indicadores de mobilidade urbana e buscam estratégias para os desafios enfrentados no processo de tomada de decisão na gestão, para a materialização de políticas públicas de mobilidade urbana sustentável. No entanto, nenhum aponta para os critérios de priorização na fase de execução dos projetos diante da limitação de recursos. Por outro lado, a literatura também identifica dificuldades do poder público municipal na implementação das políticas de mobilidade urbana, destacando como desafios a falta de experiência do corpo técnico na 
elaboração de soluções e o financiamento inapropriado, tanto para a preparação do plano quanto para sua implantação, conforme aponta May (2014).

Assim, o presente trabalho tem como escopo o processo decisório na fase de execução das políticas públicas de mobilidade urbana, tendo como objetivo maior estruturar um modelo de apoio à decisão para a escolha de projetos prioritários que concretizam as políticas públicas de mobilidade urbana, identificando os fatores e os pontos de vistas distintos de gestores e especialistas em mobilidade urbana. Para o desenvolvimento do modelo foi utilizado o método AHP, Analytic Hierarchy Process, ou Processo Hierárquico Analítico com a participação de especialistas e gestores públicos de três cidades de médio porte do Vale da Paraíba, estado de São Paulo.

\section{Referencial Teórico}

A problemática dos conflitos do tráfego e da mobilidade surgiram nos centros urbanos em função do modelo de desenvolvimento e as políticas de transportes adotados até os dias atuais. Fato demonstrado pela política de priorização do transporte individual adotada, em detrimento do transporte coletivo, apesar da grande demanda deste último, pelas classes menos favorecidas economicamente (Hidalgo e Huizenga, 2013; Moraes e Santos, 2020). As políticas de mobilidade urbana devem ser formuladas levando-se em consideração as necessidades da população envolvida, com a participação desta nas discussões e no planejamento, buscando promover a cidadania e a inclusão social (Gonçalves, 2015). O Município ao elaborar sua política urbana, deve se apoiar em diretrizes voltadas para garantir cidades justas, em que todos, pobres e ricos, desfrutem dos benefícios de uma boa gestão. Ou seja, não basta captar e interpretar as visões e desejos dos atores, mas a compatibilização dos objetivos de uma comunidade levando em conta os recursos disponíveis, para então definir estratégias sustentáveis e satisfatórias à necessidade coletiva (Lopez, 2014).

Assim como ocorreu com o Estatuto da Cidade, a Política Nacional de Mobilidade Urbana (PNMU) prevê que os municípios com mais de 20 mil habitantes elaborem seu Plano de Mobilidade Urbana, adotando os mesmos moldes do Plano Diretor (Brasil, 2012). A Lei 12.597/12 tem papel fundamental no planejamento de mobilidade urbana das cidades, uma vez que a partir dela, os municípios ficam obrigados não apenas a elaborar seus planos de mobilidade urbana, como também a seguir as diretrizes por ela apontadas na efetivação das políticas públicas. A partir das diretrizes apontadas pela Política Nacional de Mobilidade Urbana são elaborados os planos de mobilidade urbana municipais, que podem ser instrumentalizado por lei municipal específica, ou fazer parte do plano diretor municipal, compondo uma de suas seções. São previstas audiências públicas na cidade, para que a população tenha a oportunidade de se manifestar e apontar suas necessidades em relação à mobilidade urbana, visando garantir um processo democrático na sua implementação (Brasil, 2007). Em nível organizacional, a mobilidade urbana é um assunto complexo por envolver variadas instituições - governamentais, operadores privados e organizações da sociedade civil. Além disso, envolve diversos tipos de serviço - transportes coletivos, transportes não motorizados, infraestrutura dos modos de transportes, passeio público e serviços de informação -, que torna a sua complexidade ainda superior (Morais e Santos, 2020). A Figura 1 ilustra o fluxo do processo decisório no planejamento e implementação de projetos de transportes, quando o foco é a mobilidade urbana sustentável.

É importante que prefeituras municipais se baseiem nas diretrizes apontadas pela Política Nacional de Mobilidade Urbana, como um eixo da política de desenvolvimento urbano, buscando romper com as antigas práticas do urbanismo brasileiro que replicam o modelo das grandes cidades e priorizam o fluxo de trânsito para automóveis (Carvalho, et al, 2020), mas que seja realizado um diagnóstico completo das necessidades da população e das especificidades de cada cidade. Embora haja avanços no reconhecimento do tema da mobilidade urbana por parte do Poder Público Federal, há fragilidades nessa política que comprometem a sua efetividade (Morais e Santos, 2020).

A lei não expressa a tipologia do Plano de Mobilidade, se ele deve ser apresentado em forma de lei municipal, a 
exemplo do Plano Diretor, ou por meio de um documento de referência de política pública. Isso pode resultar em perda de efetividade, por não haver um guia nem a obrigatoriedade para o Poder Público Municipal executar as políticas referentes a lei (Lima e Galindo, 2013). Na ausência do Plano de mobilidade Urbana, os projetos de transportes e mobilidade urbana são elaborados e executados com base em conhecimento adquirido com o passar dos anos e as vezes sem critérios de seleção e de prioridades. As intervenções em transportes representam um elemento facilitador das relações econômicas e sociais, o que leva a percepção social de desenvolvimento, dificultando a criticidade e estimulando iniciativas de implementação dessas estruturas. Porém, sem uma contextualização que permita a análise da amplitude dos efeitos de tais medidas, concentrando-se apenas nos resultados imediatos de viabilização da circulação, sem observar os impactos socioambientais de mais longo prazo.

Figura 1 - Processo Decisório no planejamento e implementação de projetos de transportes.

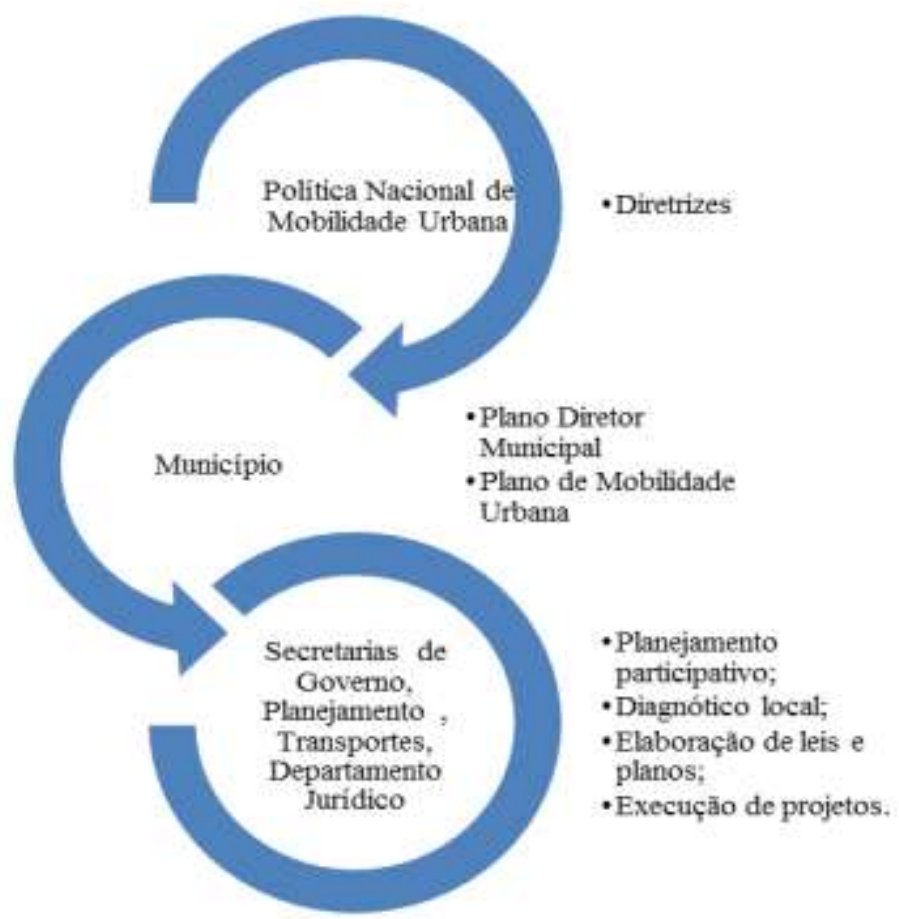

Fonte: Autores.

Como forma de sistematizar o processo de implementação das políticas públicas, é importante criar instrumentos de apoio a decisão na alocação de recursos financeiros e humanos e assim priorizando aqueles que implementam as políticas de Mobilidade Urbana mais adequadas ao contexto do Município. As fases de elaboração e execução podem passar por avaliação e análise considerando diversos aspectos e critérios de decisão (Lima et al., 2019; Malczewski, 2006). Neste sentido a abordagem de decisão multicritério mostra-se importante ferramenta, porque muitos problemas de decisão não podem ser solucionados baseando-se em apenas um critério de avaliação.

De acordo com Felix et al. (2019), as técnicas de análise multicritério viabilizam a tomada de decisão quando os problemas apresentam aspectos que vão além da tangibilidade. Com elas é possível estabelecer prioridades, tornar o processo de decisão mais racional e robusto ao incorporar à análise informações qualitativas relevantes. Esse é o caso de projetos na área de transportes, que demandam avaliação não só de aspectos técnicos e econômicos, como também de aspectos sociais, políticos e ambientais. A aplicação de métodos multicritério pode ser de natureza simples ou combinada, com uma gama de metodologias que propõem a combinação de técnicas e abordagens. Quanto a sua aplicação na área de transportes, de acordo com (Felix et al., 2019), os métodos AHP, ANP, ELECTRE e MAUT se mantêm na literatura mais atual, em detrimento de 
métodos como Regime e tipologia Adam, citados pelos autores. Destaque seja dado ao AHP, com 25,64\% de ocorrência entre todos os artigos levantados pelo presente trabalho. Portanto, no trabalho em questão será utilizado o método AHP, por definir de forma prática e eficiente os julgamentos dos decisores, passando por análise de consistência

\section{Metodologia}

Todo procedimento metodológico foi baseado nas etapas pertinentes ao processo de tomada de decisão multicritério, com o uso do método AHP. (Saaty, 2008; Lima e Machado, 2019; Caprioli e Botero, 2021). As etapas de desenvolvimento do trabalho são apresentadas pela Figura 2.

Figura 2 - Procedimento metodológico.

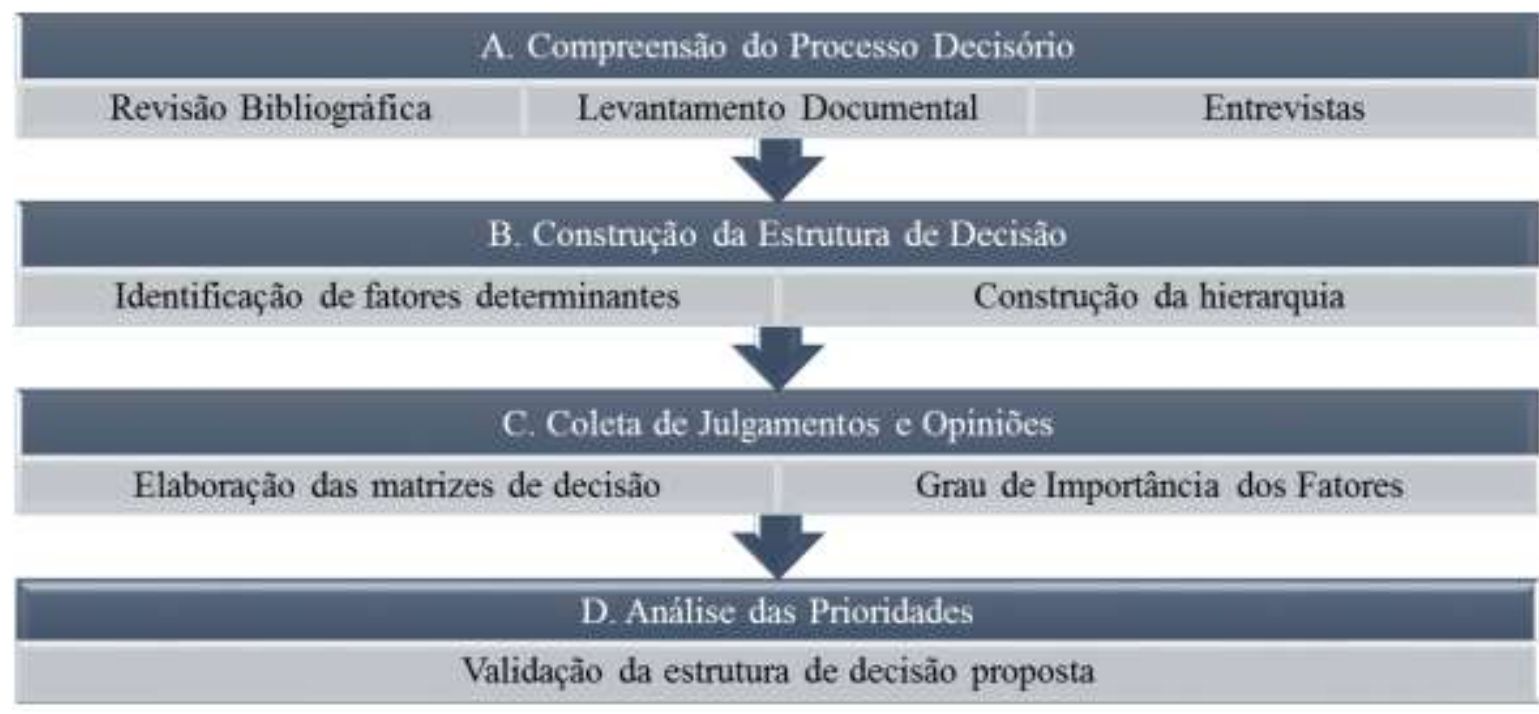

Fonte: Autores.

Na primeira etapa do trabalho, Compreensão do Processo decisório, foi feito um levantamento bibliográfico afim de compreender o papel das políticas públicas de mobilidade urbana para o desenvolvimento das cidades, além de delimitar o objeto de estudo. Uma vez determinadas as cidades estudadas, foi feito um levantamento documental para a compreensão da estrutura dessas cidades, em relação ao histórico de desenvolvimento, importância regional, população e os institutos legais que direcionam a gestão municipal de mobilidade urbana. Nesta fase também foi feita a estruturação da entrevista utilizada como ferramenta para a realização da pesquisa de campo. A entrevista foi aplicada com oito gestores das cidades, entre secretários, subsecretários e técnicos de planejamento urbano e transportes, com o objetivo de validar o que já havia sido absorvido na literatura sobre o processo decisório, o que contribuiu com a fase seguinte de construção da estrutura de decisão.

$\mathrm{Na}$ segunda etapa do trabalho, tendo como base as entrevistas realizadas anteriormente, foram determinados os fatores relevantes e depois foram agrupados em uma estrutura hierárquica. A estrutura hierárquica tem como objetivos fornecer uma visão geral das interações complexas inerentes à situação (Saaty, 2008).

A terceira etapa foi a coleta de julgamentos e opiniões de especialistas para a determinação dos pesos dos elementos do modelo de decisão. Para a coleta de opinião, foram desenvolvidas 5 matrizes de comparação par a par por meio de planilhas eletrônicas que foram enviadas aos oito gestores e mais seis especialistas acadêmicos da área de mobilidade urbana. A escala adotada para a determinação da importância relativa é apresentada na Figura 3. 
Figura 2 - Escala de comparação de critérios.

\begin{tabular}{|c|c|c|c|c|c|c|c|c|}
\hline $1 / 6$ & $1 / \sqrt{7}$ & $1 / 5$ & $\mathrm{I} / \mathrm{B}$ & I & 3 & $\$$ & 7 & 9 \\
\hline $\begin{array}{l}\text { extrema } \\
\text { micnte }\end{array}$ & hastante & maito & pouco & igual & pouc & meit & basta: & $\begin{array}{l}\text { extrema } \\
\text { mente }\end{array}$ \\
\hline \multicolumn{4}{|c|}{ MENOS IMPORTANTE } & & \multicolumn{4}{|c|}{ MAIS IMPORTANTE } \\
\hline
\end{tabular}

Fonte: Adaptado de Saaty (1990).

Os cálculos para a obtenção da importância relativa dos critérios também foram baseados em Saaty (1990). O AHP fundamenta-se na facilidade que a mente humana possui em realizar comparações entre dois objetos dentro de uma mesma classe, o que é chamado de pairwise comparisons (Lima et al., 2019; Lima e Machado, 2019). Conforme a Equação 1 o valor $a_{i j}$ se refere à importância do critério da linha i em relação ao critério da coluna j (Saaty, 1990).

$$
a_{i j}=\frac{1}{a_{j i}} \text { para } i \neq j \text { e } \quad a_{i j}=1 \text { para } i=j
$$

Por meio da matriz de comparação (A), é calculada a matriz de comparação normalizada (A'). Os valores que compõem a matriz normalizada ( $\left.\mathrm{a}^{\prime}{ }_{\mathrm{ij}}\right)$ são calculados dividindo cada valor da matriz A pelo somatório dos valores da coluna ao qual ele pertence, conforme a equação (2). Os pesos dos critérios são obtidos por meio do cálculo do autovetor, ou vetor prioridade, que é resultado da divisão entre o somatório dos valores da linha da matriz normalizada pela quantidade de critérios (n), conforme equação 3. O método também permite determinar a consistência dos julgamentos para a tomada de decisão, realizada com o cálculo da Razão de Consistência- RC (Consistency Ratio) (Saaty, 1990).

$$
\begin{aligned}
& a_{i j}^{i}=\frac{a_{i j}}{\sum_{i=1}^{n} a_{i j}} \\
& w_{i}=\frac{\sum_{j=1}^{n} a_{i j}^{y}}{n}
\end{aligned}
$$

$\mathrm{Na}$ última etapa do trabalho, foi feita a análise de prioridade de dois projetos na área de mobilidade urbana para a validação da estrutura de decisão proposta. Para determinar a prioridade dos projetos, foi calculado o Índice de Prioridade (IP), Equação 4, por meio do método de combinação linear ponderada, ou do inglês Weighted Linear Combination, WLC, (Lima et al.,2019), que combina os fatores por meio de uma média ponderada que considera os pesos de todos fatores e, também, o desempenho dos projetos à luz de cada fator influente.

$$
I P=\sum_{i=1}^{n} w_{f d i} w_{f i i} x_{i}
$$

Em que:

- $\quad$ IP = Índice de prioridade do projeto;

- $\quad \mathrm{W}_{\mathrm{fdi}}=$ Peso atribuído por gestores e especialistas da área acadêmica para o fator determinante ao qual pertence o fator influente $\mathrm{i}$;

- $\quad \mathrm{W}_{\text {fii }}=$ Peso atribuído ao fator influente i por gestores e especialistas da área acadêmica;

- $\mathrm{x}_{\mathrm{i}}=$ desempenho do projeto à luz do fator influente $\mathrm{i}$. 
O procedimento de coleta de dados foi realizado em três cidades da Região Metropolitana do Vale do Paraíba e Litoral Norte (RMVPLN), sendo elas: Lorena com população de 86.764 habitantes, Guaratinguetá com população de 118.378 habitantes e Cruzeiro, com 80.749 habitantes. As cidades foram escolhidas dentre as cidades de porte médio da região, com densidade demográfica, extensão territorial e índices de desenvolvimento semelhantes. São cidades com origem histórica predominantemente agrária, que nas últimas décadas viveram um rápido e desordenado processo de crescimento industrial e urbano e atraem diariamente um grande número de pessoas de cidades vizinhas. Possuem, portanto, papel centralizador na região que ocupam, segundo o IBGE (2010), sendo centros importantes em diversos setores: industrial, comercial, turístico e educacional.

\section{Resultados e discussão}

\subsection{Fatores determinantes no processo decisório e estruturação hierárquica}

Depois da determinação dos fatores com a colaboração dos gestores públicos e as práticas adotadas nas três cidades estudadas, a estrutura de decisão tomou um corpo de 2 níveis (Nível 1 - Fatores influentes e Nível 2 - Fatores determinantes), conforme Figura 4.

Figura 3 - Modelo hierárquico de priorização de projetos

\begin{tabular}{|c|c|c|c|c|c|c|c|c|c|c|c|}
\hline Objetivo & \multicolumn{11}{|c|}{ Priorizaça de Projetos de Transportes. } \\
\hline Fatores determinantes & & A & & & & & C & & & D. & \\
\hline Fatores Influentes & Al & $\mathrm{A} 2$ & A3 & B1 & B2 & $\mathrm{Cl}$ & $\mathrm{C}_{2}$ & C3 & D1 & D2 & D3. \\
\hline
\end{tabular}

Os fatores influentes foram divididos em 4 grupos (fatores determinantes), sendo esses: Origem, Fatores técnicos, Fatores Econômicos e Impacto socioambiental, como apresentado no Quadro 1. Mais especificamente sobre os fatores de origem, os projetos podem estar incluídos na política urbanística, ou seja, estão previstos no Plano diretor ou no Plano de Mobilidade Urbana do munícipio. Os projetos também podem ter origem em acordos ou convênios entre o município e outros entes da federação, como Governo Federal, Estadual ou Municípios vizinhos. Esses convênios podem ser firmados a partir de emendas parlamentares, que se constituem de verbas externas trazidas para o município por intermédio do poder legislativo. Por último, os projetos podem ter origem de uma demanda pontual da população. Esta demanda pode ser uma emergência de infraestrutura ou a uma necessidade que tenha surgido na sociedade posteriormente à elaboração ou revisão do Plano Diretor ou de Mobilidade e antes da próxima revisão.

Os fatores técnicos referem-se à intervenção da obra em si e estão relacionados ao tempo de execução da obra que poderá ser de longo, médio ou curto prazo, e aos transtornos na circulação durante a execução do projeto, que podem representar um obstáculo para a sua execução, como fechamento de vias e desvios de percursos. Os fatores econômicos dizem respeito à natureza do recurso destinado para a execução da obra. O investimento pode ser privado, quando a iniciativa privada tem interesse na execução da obra como, por exemplo, a construção de acesso para as instalações de uma fábrica. O recurso também pode ter origem nos próprios convênios externos firmados com o Estado, a União ou ainda ser complementado por emendas parlamentares, que são verbas advindas de parcerias entre o poder legislativo municipal e o estadual ou federal, ou ainda pode ser originário de recursos públicos da própria prefeitura, ou seja, recurso interno.

Por último, os fatores de impacto socioambiental da intervenção ponderam os efeitos sociais e ambientais do projeto. A percepção social refere-se à parcela da população que se beneficiará com a intervenção e consiste em um fator de natureza subjetiva, uma vez que analisa se a intervenção terá uma boa aceitação da população e se os impactos positivos serão maiores 
que os negativos que a alteração poderá causar. A integração do projeto com outro já existente também faz parte deste grupo e se mostrou importante na avaliação dos gestores dentro deste grupo, bem como os projetos que incentivam o uso do transporte coletivo ou dos transportes não motorizados, pois atendem à política urbana proposta pela Constituição Federal e reafirmada pelo Estatuto da Cidade e pela PNMU.

O Quadro 1 apresenta a descrição e as métricas (forma como os desempenhos de cada fator influente foram mensurados) dos fatores determinantes e influentes do processo de decisão.

Quadro 1 - Fatores determinantes e influentes no processo decisório

\begin{tabular}{|c|c|c|c|c|}
\hline $\begin{array}{c}\text { Fator } \\
\text { determinante }\end{array}$ & Descrição & Fator influente & Descrição & Métrica ou desempenho \\
\hline \multirow{3}{*}{$\begin{array}{c}\text { Origem da } \\
\text { Demanda [A] }\end{array}$} & \multirow{3}{*}{$\begin{array}{l}\text { Refere-se ao } \\
\text { ponto de partida, } \\
\text { de onde surge a } \\
\text { necessidade de } \\
\text { elaboração ou } \\
\text { execução do } \\
\text { projeto. }\end{array}$} & $\begin{array}{c}\text { Política } \\
\text { urbanística ou de } \\
\text { mobilidade [A1] }\end{array}$ & $\begin{array}{l}\text { Previsão do projeto no Plano Diretor } \\
\text { ou Plano de Mobilidade Urbana da } \\
\text { cidade, possuindo, portanto, } \\
\text { obrigatoriedade de execução } \\
\text { legalmente prevista }\end{array}$ & $\begin{array}{l}\text { Análise binária, verificando-se a } \\
\text { presença (valor 1) ou não (valor 0) do } \\
\text { projeto no Plano Diretor ou Plano de } \\
\text { Mobilidade Urbana do município. }\end{array}$ \\
\hline & & $\begin{array}{l}\text { Demanda pontual } \\
\text { da população [A2] }\end{array}$ & $\begin{array}{l}\text { Projetos que se tornam necessários de } \\
\text { acordo com o crescimento da cidade e } \\
\text { que não estão previstos na sua política } \\
\text { urbana, uma vez que esta deve ser } \\
\text { revista a cada dez anos. }\end{array}$ & $\begin{array}{l}\text { Análise binária, averiguando se o } \\
\text { projeto, não estando previsto na } \\
\text { política urbanística da cidade, foi } \\
\text { elaborado (valor } 1 \text { ) ou não (valor } 0 \text { ) } \\
\text { para atender uma necessidade apontada } \\
\text { pela população }\end{array}$ \\
\hline & & $\begin{array}{c}\text { Convênios } \\
\text { Externos [A3] }\end{array}$ & $\begin{array}{l}\text { São acordos firmados entre o } \\
\text { município e outro ente federado, como } \\
\text { União, Estado ou municípios vizinhos, } \\
\text { que tem como objetivo a realização do } \\
\text { projeto. Na maioria dos casos, esses } \\
\text { projetos têm prazo para serem } \\
\text { executados, sob pena de o município } \\
\text { sofrer sanções por parte da União ou } \\
\text { Estado }\end{array}$ & $\begin{array}{l}\text { Análise binária, verificando se o } \\
\text { projeto é (valor 1) ou não é (valor 0) } \\
\text { objeto de algum acordo ou convênio } \\
\text { entre o município com outro ente } \\
\text { federado. }\end{array}$ \\
\hline \multirow[b]{2}{*}{$\begin{array}{c}\text { Fatores } \\
\text { Técnicos [B] }\end{array}$} & \multirow{2}{*}{$\begin{array}{l}\text { Verifica se } \\
\text { poderá haver } \\
\text { dificuldades/com } \\
\text { plexidade durante } \\
\text { a execução da } \\
\text { obra }\end{array}$} & $\begin{array}{c}\text { Prazo de Execução } \\
\text { [B1] }\end{array}$ & $\begin{array}{l}\text { Tempo estimado para a finalização da } \\
\text { obra, podendo ser de curto, médio e } \\
\text { longo prazo }\end{array}$ & $\begin{array}{l}\text { Verifica-se o tempo previsto para a } \\
\text { execução do projeto: Curto prazo: até } \\
1 \text { ano (valor } 1 \text { ); Médio prazo: de } 1 \text { a } 3 \\
\text { anos (valor } 0,5 \text { ) ; Longo prazo: mais do } \\
\text { que } 3 \text { anos para efetivação do projeto } \\
\text { (valor } 0,2 \text { ). }\end{array}$ \\
\hline & & $\begin{array}{l}\text { Intervenções na } \\
\text { circulação [B2] }\end{array}$ & $\begin{array}{l}\text { A fase de execução de um projeto de } \\
\text { mobilidade urbana pode trazer alguns } \\
\text { transtornos na circulação que refletem } \\
\text { na rotina da população e precisam ser } \\
\text { previamente analisados no intuito de } \\
\text { minimizá-los. }\end{array}$ & $\begin{array}{l}\text { Avaliado quanto ao impacto no } \\
\text { trânsito: Baixo (Valor 1): quando não } \\
\text { há fechamento de vias ou desvios, } \\
\text { apenas com sinalização da obra; Médio } \\
\text { (valor 0,5): com desvios e lentidão na } \\
\text { circulação; Alto (valor 0,2): quando há } \\
\text { necessidade de fechamento de vias. }\end{array}$ \\
\hline \multirow{3}{*}{$\begin{array}{l}\text { Fatores } \\
\text { econômicos } \\
{[\mathrm{C}]}\end{array}$} & \multirow{3}{*}{$\begin{array}{l}\text { Relacionado à } \\
\text { natureza do } \\
\text { recurso a ser } \\
\text { utilizado na } \\
\text { execução do } \\
\text { projeto. }\end{array}$} & $\begin{array}{l}\text { Recurso público } \\
\text { externo [C1] }\end{array}$ & $\begin{array}{l}\text { O recurso para o projeto tem origem } \\
\text { no governo federal ou estadual, } \\
\text { destinado ao município para execução. }\end{array}$ & \multirow{3}{*}{$\begin{array}{l}\text { Análise binária nos três casos, com } \\
\text { valor } 1 \text {, se tiver o recurso ou valor } 0 \text { se } \\
\text { não advir do recurso analisado. Vale } \\
\text { esclarecer que um mesmo projeto pode } \\
\text { ter recursos de mais de uma fonte ou } \\
\text { mesmo das três origens explicadas } \\
\text { acima. }\end{array}$} \\
\hline & & $\begin{array}{l}\text { Recurso público } \\
\text { Interno [C2] }\end{array}$ & $\begin{array}{l}\text { O município conta apenas com } \\
\text { recursos próprios para a execução do } \\
\text { projeto. }\end{array}$ & \\
\hline & & $\begin{array}{l}\text { Recurso de fins } \\
\text { privado [C3] }\end{array}$ & $\begin{array}{l}\text { O município conta com recurso } \\
\text { advindo da iniciativa privada para } \\
\text { realizar o projeto. }\end{array}$ & \\
\hline
\end{tabular}




\begin{tabular}{|c|c|c|c|c|}
\hline \multirow{3}{*}{$\begin{array}{c}\text { Impacto } \\
\text { socioambientai } \\
\text { S [D] }\end{array}$} & \multirow{3}{*}{$\begin{array}{l}\text { Relacionado aos } \\
\text { efeitos sociais e } \\
\text { ambientais do } \\
\text { projeto }\end{array}$} & $\begin{array}{c}\text { Percepção social } \\
\text { [D1] }\end{array}$ & $\begin{array}{l}\text { Analisa a parcela da população que se } \\
\text { beneficiará com a intervenção, possui } \\
\text { natureza subjetiva, pois avalia se a } \\
\text { intervenção terá uma boa aceitação da } \\
\text { população e se os benefícios serão } \\
\text { maiores que os prejuízos que a } \\
\text { alteração poderá causar. }\end{array}$ & $\begin{array}{l}\text { Análise binária, avaliando o grau de } \\
\text { satisfação da população com a } \\
\text { intervenção, para isso é necessário um } \\
\text { estudo prévio de impacto social para } \\
\text { avaliar se a receptividade da população } \\
\text { envolvida será positiva (valor 1) ou } \\
\text { negativa (valor 0). }\end{array}$ \\
\hline & & $\begin{array}{c}\text { Integração entre } \\
\text { projetos [D2] }\end{array}$ & $\begin{array}{l}\text { Verifica se o projeto está relacionado } \\
\text { a outro projeto já existente, dando } \\
\text { continuidade ou complementando-o. }\end{array}$ & $\begin{array}{l}\text { Análise binária, avaliando a existência } \\
\text { (valor 1) ou não (valor 0) de integração } \\
\text { com outros projetos. }\end{array}$ \\
\hline & & $\begin{array}{c}\text { Incentivo ao } \\
\text { transporte coletivo } \\
\text { ou não motorizado } \\
{[\text { [D3] }}\end{array}$ & $\begin{array}{l}\text { Está relacionado a uma das diretrizes } \\
\text { apontadas pela Política Nacional de } \\
\text { Mobilidade Urbana, com o intuito de } \\
\text { minimizar os transtornos ambientais e } \\
\text { sociais causados pelo excesso de } \\
\text { veículos e melhorar a qualidade de } \\
\text { vida da população local. }\end{array}$ & $\begin{array}{l}\text { Análise binária, considerando se o } \\
\text { projeto está ligado (valor 1) ou não } \\
\text { (valor 0) ao uso de transporte coletivo } \\
\text { ou não motorizado. }\end{array}$ \\
\hline
\end{tabular}

Fonte: Autores.

\subsection{Importância relativa dos fatores de decisão}

A Tabela 1 apresenta o peso dos fatores influentes $\left(\mathrm{w}_{\mathrm{fi}}\right)$ e dos fatores determinantes $\left(\mathrm{w}_{\mathrm{fd}}\right)$, segundo a opinião dos gestores e especialistas. $\mathrm{O}$ valor final dos pesos foi calculado por meio de uma média considerando todos os pesos atribuídos por ambos os grupos. Em relação aos fatores determinantes, tanto os gestores quanto os especialistas concordam que a "Origem da demanda" é o critério que possui maior grau de importância no processo de decisão, com peso de 0,510 para os gestores e 0,301 para os especialistas. Verifica-se uma maior diferença na opinião quanto aos demais fatores determinantes.

Tabela 1 - Pesos dos fatores envolvidos no processo decisório.

\begin{tabular}{|c|c|c|c|}
\hline \multirow[b]{2}{*}{ Fatores Determinantes } & \multicolumn{2}{|c|}{$\mathbf{W}_{\mathbf{f d}}$} & \multirow[b]{2}{*}{$\begin{array}{c}\text { Pesos } \\
\text { Finais }\end{array}$} \\
\hline & Gestores & Especialistas & \\
\hline Origem da demanda & 0,510 & 0,301 & 0,421 \\
\hline Fatores Técnicos & 0,093 & 0,197 & 0,137 \\
\hline Fatores econômicos & 0,076 & 0,252 & 0,151 \\
\hline Fatores Socioambientais & 0,321 & 0,250 & 0,291 \\
\hline \multirow{2}{*}{ Fatores Influentes } & \multicolumn{2}{|c|}{$\mathbf{W f i}$} & Pesos \\
\hline & Gestores & Especialistas & Finais \\
\hline Política Urbanística & 0,526 & 0,511 & 0,520 \\
\hline Demandas Pontuais & 0,254 & 0,379 & 0,307 \\
\hline Convênios Externos & 0,220 & 0,110 & 0,173 \\
\hline Prazo de execução & 0,208 & 0,598 & 0,375 \\
\hline Intervenções na circulação & 0,792 & 0,402 & 0,625 \\
\hline Recurso Privado & 0,390 & 0,314 & 0,358 \\
\hline Recurso Interno & 0,427 & 0,330 & 0,386 \\
\hline Recurso Externo & 0,183 & 0,356 & 0,256 \\
\hline Percepção social & 0,419 & 0,294 & 0,366 \\
\hline Integração entre projetos & 0,096 & 0,303 & 0,184 \\
\hline $\begin{array}{l}\text { Incentivo a transportes não } \\
\text { motorizados ou coletivos }\end{array}$ & 0,485 & 0,403 & 0,450 \\
\hline
\end{tabular}


Os pesos foram distribuídos de forma mais igualitária entre os fatores técnicos $(0,197)$, fatores econômicos $(0,252)$ e fatores socioambientais $(0,250)$ conforme julgamento dos especialistas. Já para os gestores públicos, seguido do grupo "Fatores de Origem", o grupo de fatores socioambientais apresentou um peso relativamente maior $(0,321)$ quando comparado com os demais. Considerando a opinião de ambos os grupos, o fator determinante "Origem da demanda" foi o de maior peso no processo decisório, seguido por fatores socioambientais, fatores econômicos e, por último, fatores técnicos.

No grupo "Fatores Técnicos" observa-se divergência de opinião entre especialistas e gestores. Para os primeiros, o prazo de execução é mais importante (0,598), o que não se repete para os gestores, que atribuíram um peso de 0,208 para este fator. Isso ocorre pois, na prática, é necessário, primeiramente, analisar o impacto das intervenções na circulação, que implicam em interferências na rotina da população, no trânsito, na organização de funcionários para sinalização, entre outras medidas. No resultado final, o fator intervenção na circulação obteve maior peso $(0,625)$ do que o prazo na execução $(0,375)$.

Também foi observada divergência de opinião entre os "Fatores Econômicos". Os resultados mostram que, para os especialistas, a origem do recurso não é relevante na priorização dos projetos. Isto é observado pelos pesos atribuídos à natureza do recurso que foram praticamente os mesmos: recurso privado $(0,314)$, recurso interno $(0,330)$ e recurso externo $(0,356)$. Para os gestores, a diferença de pesos é mais significativa dentro deste grupo, sendo o recurso público interno mais importante na avaliação $(0,427)$. Esse fato pode ser explicado porque na prática, os projetos para os quais a Prefeitura já conta com recursos próprios para concretização são priorizados, enquanto os outros que dependem de recurso de outra natureza precisam aguardar a verba para execução. Sendo assim, de forma geral, o fator recurso interno apresenta maior peso $(0,386)$, seguido por recurso privado $(0,358)$ e recurso externo $(0,257)$.

Em relação aos fatores influentes do grupo "Impacto socioambiental", para os gestores, o incentivo ao transporte coletivo e aos não motorizados $(0,485)$ juntamente com a percepção social $(0,419)$ apresentaram maior peso do que o fator integração entre projetos $(0,094)$. Mais especificamente sobre a percepção social, para agentes públicos, a aprovação da população é bastante relevante e algumas vezes não é interessante dar continuidade a projetos iniciados em outra gestão, o que pode ter levado a um baixo peso para o fator integração entre projetos. Para os especialistas, dentro deste grupo, o incentivo aos modos de transportes não motorizados e coletivo também é de maior relevância $(0,403)$, seguido da integração entre os projetos $(0,303)$.

Quanto aos fatores influentes do grupo "Origem da demanda", há convergência nas opiniões de técnicos gestores e especialistas, que consideram a previsão do projeto no Plano Diretor ou Plano de Mobilidade Municipal mais importante que os fatores "Demanda Pontual" e "Convênios externos". A ordem de prioridade dentro deste grupo foi: Política urbanística $(0,526)$, demandas pontuais $(0,307)$ e convênios externos $(0,173)$

É importante destacar que os fatores propostos na pesquisa foram determinados pela observação dos processos decisórios nas cidades estudadas e indicados pelos gestores, baseados na experiência vivenciada por eles. Apesar disto, os especialistas da área acadêmica foram consultados na fase de atribuição de pesos para verificar se os fatores determinados possuem relação com os conceitos teóricos para o alcance da mobilidade urbana sustentável. Ressalta-se que todos especialistas da área acadêmica confirmaram que consideram os fatores elencados neste trabalho relevantes para o processo decisório. Sendo assim, conclui-se que as diferenças nas opiniões entre gestores e especialistas se devem ao fato de que os gestores analisam os fatores considerando a prática da priorização de projetos e a complexidade de sua execução.

\subsection{Aplicação do modelo por meio do cálculo do índice de prioridade}

O modelo foi validado por meio de sua aplicação para a comparação da prioridade de dois projetos de mobilidade urbana em um dos municípios estudados, sendo esses: 
- Projeto A1 = construção de uma ciclofaixa de 1,3 quilômetros, ligando o centro da cidade a um bairro populoso, destinado ao uso residencial e comercial;

- Projeto A2 = implantação de semáforos em uma avenida que liga a entrada principal ao centro da cidade.

A prioridade de cada projeto foi determinada pelo Índice de Prioridade apresentado pela Equação 4, que agrega os pesos dos fatores determinantes $\left(\mathrm{W}_{\mathrm{fd}}\right)$, pesos dos fatores influentes $\left(\mathrm{w}_{\mathrm{i}}\right)$, ambos apresentados no Tabela 1, e o desempenho do projeto à luz do fator influente. O desempenho em relação a cada foi determinado conforme descrito no Quadro 1. A Tabela 2 apresenta todos os valores utilizados para o cálculo do IP, bem como os índices por grupo e o índice global.

Tabela 2 - Índice de prioridade por projeto.

\begin{tabular}{|c|c|c|c|c|c|c|c|c|c|}
\hline \multirow{2}{*}{$\begin{array}{c}\text { Fator } \\
\text { determinante }\end{array}$} & \multirow{2}{*}{$\mathbf{w}_{\mathrm{fd}}$} & \multirow{2}{*}{ Fator Influente } & \multirow{2}{*}{$\mathbf{w}_{\mathrm{fi}}$} & \multicolumn{2}{|c|}{$\mathbf{x}_{\mathbf{i}}$} & \multicolumn{2}{|c|}{$\begin{array}{c}\text { Valores } \\
\text { ponderados }\end{array}$} & \multicolumn{2}{|c|}{$\begin{array}{c}\text { Valores } \\
\text { agrupados }\end{array}$} \\
\hline & & & & A1 & $\mathbf{A 2}$ & A1 & A2 & A1 & A2 \\
\hline \multirow{3}{*}{ Origem } & \multirow{3}{*}{0,421} & $\begin{array}{l}\text { Política Urbanística ou de } \\
\text { mobilidade }\end{array}$ & 0,520 & 1 & 0 & 0,520 & 0,000 & \multirow{3}{*}{0,827} & \multirow{3}{*}{0,307} \\
\hline & & Demanda da população & 0,307 & 1 & 1 & 0,307 & 0,307 & & \\
\hline & & Convênios externos & 0,173 & 0 & 0 & 0,000 & 0,000 & & \\
\hline \multirow[b]{2}{*}{ Fatores técnicos } & \multirow[b]{2}{*}{0,137} & Prazo de execução & 0,375 & 1 & 1 & 0,375 & 0,375 & \multirow[b]{2}{*}{1,000} & \multirow[b]{2}{*}{0,688} \\
\hline & & $\begin{array}{l}\text { Intervenções na } \\
\text { circulação }\end{array}$ & 0,625 & 1 & 0,5 & 0,625 & 0,313 & & \\
\hline \multirow{3}{*}{$\begin{array}{l}\text { Fatores } \\
\text { econômicos }\end{array}$} & \multirow{3}{*}{0,151} & Recurso Privado & 0,358 & 0 & 0 & 0,000 & 0,000 & \multirow{3}{*}{0,386} & \multirow{3}{*}{0,386} \\
\hline & & Recurso Interno & 0,386 & 1 & 1 & 0,386 & 0,386 & & \\
\hline & & Recurso Externo & 0,256 & 0 & 0 & 0,000 & 0,000 & & \\
\hline \multirow{4}{*}{$\begin{array}{l}\text { Fatores } \\
\text { socioambientais }\end{array}$} & \multirow{3}{*}{0,291} & Percepção social & 0,366 & 1 & 1 & 0,366 & 0,366 & \multirow{3}{*}{1,000} & \multirow{3}{*}{0,366} \\
\hline & & Integração entre projetos & 0,184 & 1 & 0 & 0,184 & 0,000 & & \\
\hline & & $\begin{array}{l}\text { Incentivo a transportes } \\
\text { não motorizados ou } \\
\text { coletivos }\end{array}$ & 0,450 & 1 & 0 & 0,450 & 0,000 & & \\
\hline & & & \multicolumn{5}{|c|}{ Índice de Prioridade } & 0,834 & 0,388 \\
\hline
\end{tabular}

Fonte: Autores.

Inicialmente foram agrupados os elementos do nível mais baixo da estrutura hierárquica, ou seja, os valores de cada projeto à luz de cada critério multiplicado pelos seus respectivos pesos. Realiza-se assim, o agrupamento por meio da soma dos valores ponderados por grupo de fatores, obtendo-se os índices de prioridades por grupo. Ressalta-se que o Índice de Prioridade é um valor entre 0 e 1 , sendo que quanto mais próximo de 1 , maior é a prioridade

Em relação ao projeto A1, implementação de uma ciclofaixa, o grupo de fatores técnicos e de fatores socioambientais foram os de maior prioridade, ambos com índice igual a 1. A implementação de ciclofaixa apresenta baixo tempo para execução e também um baixo impacto no trânsito, o que fez com o que aumentasse a prioridade deste grupo. Já a instalação do semáforo, apesar do prazo para execução também ser baixo, o impacto no trânsito é considerado médio, o que impactou no índice deste grupo para o projeto A2 (IP $=0,688$ ). Sobre os fatores socioambientais, observa-se que a implantação da ciclofaixa apresenta desempenho máximo em todos os fatores influentes. Já para o projeto A2, dentro deste grupo, apenas a percepção social apresentou um desempenho igual a 1, o que gerou um índice de prioridade igual a 0,366.

Para o cálculo do Índice de Prioridade Global, é feita a ponderação considerando também os pesos dos fatores determinantes. Pelo cálculo do índice, neste estudo de caso, a implementação da ciclofaixa apresenta maior prioridade $(0,834)$ do que a implantação do semáforo $(0,388)$. Isto não implica que em todas as situações em que os projetos comparados sejam 
cicloviários e sinalização, o resultado seja o mesmo que o encontrado neste estudo. Ocorre que fatores importantes que contemplam os pilares do desenvolvimento sustentável, entre demanda, fatores técnicos, econômicos e socioambientais, foram ponderados e cada projeto possui sua especificidade diante dos fatores de decisão, havendo uma compensação entre os que apresentaram baixos desempenhos com aqueles que apresentaram resultados melhores. Sendo assim, o modelo proposto se apresenta como uma boa ferramenta para auxiliar no processo de tomada de decisão.

\section{Conclusão}

A Mobilidade Urbana nas últimas décadas passou a ser um motivo de preocupação na elaboração de políticas públicas de desenvolvimento urbano. Entretanto, a implementação de medidas que tragam soluções sustentáveis para as condições de deslocamento no ambiente urbano enfrenta desafios difíceis de serem contornados, uma vez que para isso é necessária a reconstrução de valores atribuídos às políticas públicas, que não podem mais visar soluções imediatistas, que são apenas paliativas, e não solucionam os problemas a médio e longo prazo.

A pesquisa apontou que o processo de gestão estratégica de mobilidade urbana sustentável tem encontrado grandes desafios na escolha dos projetos que materializam as políticas públicas de mobilidade urbana sustentável, uma vez que a gestão pública trabalha com recursos limitados. Com base na metodologia de avaliação multicritério, realizou-se a ponderação de múltiplas opiniões de especialistas para determinar o grau de importância dos fatores determinantes na decisão e validar a estrutura de decisão elaborada para auxiliar a escolha dos projetos prioritários pelos gestores. A aplicação do AHP possibilitou determinar o grau de consistência dos julgamentos, comprovando a eficiência da avaliação e a relevância dos fatores considerados, uma análise considerada de extrema importância quando se trata de tomada de decisão com múltiplos critérios.

Em relação às importâncias relativas de grupos de fatores principais, o grupo "Origem da demanda" foi apontado como o mais importante, pois se refere ao motivo pelo qual o projeto se fez necessário e, nesse sentido, a previsão do projeto no Plano Diretor ou Plano de Mobilidade Municipal é o fator predominante na opinião de especialistas e gestores, o que demonstra a importância atribuída à política urbanística do município, cujo planejamento é imprescindível. As opiniões são hora divergentes e hora convergentes em relação aos fatores, entretanto, a "Origem da demanda" foi apontada como o mais importante na opinião dos especialistas e também dos gestores. Sobre os fatores influentes do grupo "Impacto Socioambiental", ambos, especialistas e gestores públicos, consideram o incentivo ao transporte coletivo e não motorizados o fator mais importante. No entanto, as opiniões se diferem quanto aos demais fatores.

Os especialistas consideram o fator "integração entre projetos" mais importante que o fator "percepção social", enquanto para os gestores ocorre o contrário. Os gestores dão grande importância à satisfação popular em relação às intervenções da administração, uma vez que a aprovação da população é interessante para que os gestores se mantenham na posição ou possam indicar seus sucessores. Além disso, dar continuidade em projetos já existentes não é interessante do ponto de vista político, pois de acordo com o sistema político atual, pode dar créditos a administrações anteriores. Já para os especialistas, dar continuidade ou complementar os projetos existentes mostrou-se mais importante que a percepção social da intervenção, uma vez que esta percepção ocorrerá a longo prazo.

Por outro lado, os resultados obtidos pelo grau de importância atribuído pelos gestores demonstram que os Fatores Econômicos não são os mais relevantes na priorização de projetos pois, segundo eles, se o projeto for necessário, procura-se unir esforços e recursos internos e externos através de emendas parlamentares ou até mesmo recursos privados. Esse é um aspecto positivo das cidades estudadas e demonstra a preocupação por parte dos gestores em seguirem as diretrizes trazidas pelo Estatuto das Cidades e Política Nacional de Mobilidade Urbana. Entretanto, o processo de adequação dos municípios à Lei 12.587/12 se mostrou incipiente, com os planos diretores e de mobilidade urbana em fase de elaboração, as políticas de 
transportes precisam se ajustar para que se alcancem os objetivos propostos pela lei federal, especialmente em relação ao desenvolvimento sustentável das cidades.

O modelo de apoio à decisão elaborado foi aplicado para dois projetos de uma das cidades estudadas, chegando-se a um resultado que apontou o projeto que, com base na estrutura elaborada, teria prioridade de execução. Desta forma a estrutura proposta foi validada, uma vez que os resultados obtidos foram condizentes com o grau de importância atribuído aos fatores identificados no processo decisório e também com os conceitos apresentados na revisão de literatura.

O trabalho atingiu seu objetivo de elaborar um modelo de tomada de decisão para priorização de projetos de mobilidade urbana que promove a análise dos projetos a partir de elementos técnicos e subjetivos permitindo a ponderação desses fatores, buscando a implementação de políticas que melhor se adequem ao contexto do município. Espera-se assim, que o presente estudo estimule outras pesquisas científicas que busquem a compreensão do processo decisório na gestão de mobilidade urbana em outras cidades e regiões, permitindo traçar comparativos, visando auxiliar o planejamento e implementação de políticas públicas que contribuam para o desenvolvimento das cidades. Sugere-se ainda, o desenvolvimento de pesquisas que avaliem as políticas públicas de mobilidade urbana implementadas em cidades de médio porte, de acordo com a política nacional de desenvolvimento urbano brasileira, instrumentalizada pelas leis $\mathrm{n}^{\circ}$. 10.257/01 (Estatuto da Cidade), $\mathrm{n}^{\circ}$. 12.587/12 (Política Nacional de Mobilidade Urbana) e $n^{\circ}$. 13.089/15 (Estatuto da Metrópole), identificando os desafios e as dificuldades, bem como soluções com resultados efetivos para o desenvolvimento sustentável das cidades.

Por fim é importante que as diretrizes da Lei 12.587/12 sejam seguidas de acordo com as características específicas de cada cidade, não apenas com a elaboração de um Plano de Mobilidade Municipal generalizado, apenas para cumprir a imposição legal e continuar a receber benefícios federais, mas que instrumentalize políticas adequadas às necessidades da população, com medidas que tragam resultados efetivos de melhoria na qualidade de vida da população.

\section{Agradecimentos}

Os autores agradecem ao CNPQ, à FAPEMIG e à CAPES pelo apoio financeiro concedido aos projetos que subsidiaram o desenvolvimento deste trabalho.

\section{Referências}

Boareto, R. A. (2008). Política de Mobilidade Urbana e a Construção de Cidades Sustentáveis. Revista dos Transportes Públicos - ANTP, ano 30/31. p. 143160. http://www.fetranspordocs.com.br/downloads/10APoliticaConstrucaoCidadesSustentaveis.pdf

BRASIL. (2012). Lei 12.587 de 3 de janeiro de 2012. Institui as diretrizes da Política Nacional de Mobilidade Urbana. Diário Oficial da União, Brasília, DF, Seção 1, p 1. 2012. http://www.planalto.gov.br/ccivil_03/_ato2011-2014/2012/lei/112587.htm.

BRASIL. (2007). Ministério das Cidades- SeMob. PlanMob - Caderno de referência para elaboração de plano de mobilidade urbana. 2007. https://itdpbrasil.org/planmob/

Campos, V. B. G. (2006). Uma Visão da Mobilidade Urbana Sustentável. Revista dos Transportes Públicos -ANTP. Ano 28. http://www.fetranspordocs.com.br/downloads/08umavisaodaMobilidadeUrbanaSustentavel.pdf.

Capriolo, C.; Bottero, M. (2021). Adressing complex challenges in transformations and planning: A fuzzy spatial multicriteria analysis for identifying suitable locations for urban infrastructures. Land Use Policy, 102, 105147. https://doi.org/10.1016/j.landusepol.2020.105147

Costa, M. C. (2008). Índice de Mobilidade Urbana Sustentável para Cidades Brasileiras. Tese (Doutorado). Escola de Engenharia de São Carlos, Universidade de São Paulo, São Carlos. www.teses.usp.br/teses/disponiveis/18/18144/tde-01112008.../Tese_MCOSTA.pdf

Croti, G. O.; Ferreira, W. G. (2020). Avaliação da acessibilidade de pessoas com mobilidade reduzida: um estudo na região central de Jaboticabal. Research, Society and Development, v.9 (1). DOI: 10.33448/rsd-v9i1.1815.

Felix, R. O.M.; Alves, V.; Lima, J.P. (2019) Land use management in the surroundings areas of the Sapucaí River in Itajubá-MG. Urbe, 11, pp.1-15. https://doi.org/10.1590/2175-3369.011.001.ao02

Fix, M.; Ribeiro, G. E.; Prado, A. D. (2015). Mobilidade urbana e direito à cidade. Revista Brasileira de Estudos Urbanos Regionais, v. 17, n.3, p.175-191, set./dez. http://dx.doi.org/10.22296/2317-1529.2015v17n3p175 
Gonçalves, F. C. C. A. (2015). Paisagem como fenômeno e objeto de interesse público: com que direito? Desenvolvimento e Meio Ambiente, vol. 34, p. 99116. http://dx.doi.org/10.5380/dma.v34i0.39224.

Guerra, A. J. B. S. O.; Pereira Ribeiro, J. M.; Fernandez, F.; Bailey, C.; Barbosa, S. B.; Neiva, S. S. (2016). The adoption of strategies for sustainable cities: A comparative study between Newcastle and Florianopolis focused on urban mobility. Journal of Cleaner Production, v. 113, p. 681-694. https://doi.org/10.1016/j.jclepro.2015.07.135

Haghshenas, H.; Vaziri, M.; Gholamialam, A. (2015). Evaluation of sustainable policy in urban transportation using system dynamics and world cities data: A case study in Isfahan. Cities, v. 45, p. 104-115. https://doi.org/10.1016/j.cities.2014.11.003

Hidalgo, D.; Huizenga, C. (2013). Implementation of sustainable urban transport in Latin America. Research in Transportation Economics, v. 40 (1) p. $66-77$. http://dx.doi.org/10.1016/j.retrec.2012.06.034.

IBGE. (2010). Instituto Brasileiro de Geografia e estatística. Cidades. http://cod.ibge.gov.br/2AJ.

Lima, J. P.; Abitante, J. C.; Dias Pons, N. A.; Senne, C. M. (2019). A spatial fuzzy multicriteria analysis of accessibility: A case study in Brazil. Sustainability (Switzerland), 11(12). https://doi.org/10.3390/su11123407.

Lima, J.P.; Machado, M. H. (2019). Walking acessibility for individuals with reduced mobility: A Brazilian case study. Case Studies on Transport Policy, 7, p. 269-279. https://doi.org/10.1016/j.cstp.2019.02.007

Lopez, C. (2014). O processo metodológico para La elaboracion de um Plan de Movilidad Urbana Sostenible. In: Anais do XXVII ANPET - Congresso da Associação Nacional de Pesquisa e Ensino em Transportes. Belém/PA.

Lucian, P. (2015). Some Considerations on the Sustainable Urban Development in Romania. Procedia Economics and Finance. v. 27, p. 574-578. https://doi.org/10.1016/S2212-5671(15)01035-7.

Machado, M. H.; Lima, J. P. (2017). Avaliação da acessibilidade pela perspectiva da pessoa com mobilidade reduzida. Revista Tecnologia e Sociedade, v.13, n. 29, p. 1-21, set./dez. 2017. https://periodicos.utfpr.edu.br/rts/article/view/5548

Maganin, R. C.; Silva, A. N. R. (2008). A percepção do especialista sobre o tema mobilidade urbana. Transportes. v. 16, nº 1, p. 25-35. 2. http://dx.doi.org/10.14295/transportes.v16i1.13.

Malczewski, J. (2006). GIS-based multicriteria decision analysis: a survey of literature. International Journal of Geographical Information Science. v. 20 n. 7. P. 703-726. http://dx.doi.org/10.1080/13658810600661508.

Martins, M. de F.; Salles, M. C. T., de Macedo, E. T.; Nunes, E. R.; Ribeiro, R. O. (2020). Problemas urbanos que interferem na sustentabilidade de cidades: um estudo no Município de Serra Redonda - Paraíba -Brasil. Research, Society and Development, v. 9(8), 1-12. DOI: 10.33448/rsd-v9i8.6177.

May, A. D. (2014). Encouraging good practice in the development of Sustainable Urban Mobility Plans. Case Studies on Transport Policy, Leeds, UK. https://doi.org/10.1016/j.cstp.2014.09.001

Miranda, H. F.; Silva, A. N. R. (2012). Benchmarking sustainable urban mobility: The case of Curitiba, Brazil. Transport Policy, v. 21, p. 141-151. http://dx.doi.org/10.1016/j.tranpol.2012.03.009

Morais, A.C.M.; Santos, E.M. dos. (2020). Avaliação das estruturas organizacionais dos organismos gestores da mobilidade diante da Política Nacional de Mobilidade Urbana. URBE, Rev. Bras. Gest. Urbana. vol.12. 2020. https://doi.org/10.1590/2175-3369.012.e20190232

Pontes, T. F. (2011). Ocupação urbana da área metropolitana de Brasília versus mobilidade urbana sustentável. CEUB, v.8, n1. 2011. https://doi.org/10.5102/uc.v8i1.1346.

Saaty.T.L. (1990). How to make a decision: The Analytic Hierarchy Process. European Journal of Operational Research, v.48, p. 9-26. http://dx.doi.org/10.1016/0377-2217(90)90057-I.

Saaty, T. L. (2008). Decision making with the analytic hierarchy process. International Journal of Services Sciences, v. 1, n. 1, p. 83-98. https://doi.org/10.1504/IJSSci.2008.01759.

Sakato, E.; Lima, J.P. (2016). Accessibility in the rural environment: a multicriteria approach using GIS. Transportes. 24(1). 63-73. http://dx.doi.org/10.14295/transportes.v24i1.958

Seabra, L. O. (2013). Fundamentos para a construção de um índice para gestão estratégica da mobilidade urbana sustentável - IGEMUS. Tese (doutorado). Universidade de Brasília. Brasília, DF. 2013. http://repositorio.unb.br/handle/10482/15733

Silva, A. N. R.; Azeda Filho, M. A. N.; Macedo, M. H.; Sorrantini, J. A.; Silva, A. F.; Lima, J. P.; Pinheiro, A. M. G. S. (2015). A comparative evaluation of mobility conditions in selected cities of the five Brazilian regions. Transport Policy, v. 37, p. 147-156. https://doi.org/10.1016/j.tranpol.2014.10.017.

Silva, A. N. R.; Costa, M. S. E.; Macedo, M. H. (2008). Multiple views of sustainable urban mobility: The case of Brazil. Transport Policy, v. 15 p. 350-360. http://doi.org/10.1016/j.tranpol.2008.12.003. 